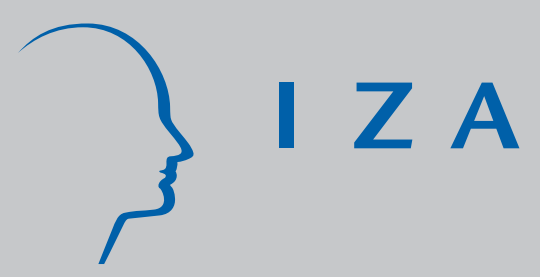

IZADP No. 2777

Intrahousehold Specialization in Housework in the United States and Denmark

J ens Bonke Mette Deding

Mette Lausten

Leslie S. Stratton

May 2007 


\title{
Intrahousehold Specialization in Housework in the United States and Denmark
}

\author{
Jens Bonke \\ Danish National Institute of Social Research \\ Mette Deding \\ Danish National Institute of Social Research \\ Mette Lausten \\ Danish National Institute of Social Research \\ Leslie S. Stratton \\ Virginia Commonwealth University and IZA
}
Discussion Paper No. 2777
May 2007

IZA
P.O. Box 7240
53072 Bonn
Germany

Phone: +49-228-3894-0

Fax: +49-228-3894-180

E-mail: iza@iza.org

\begin{abstract}
Any opinions expressed here are those of the author(s) and not those of the institute. Research disseminated by IZA may include views on policy, but the institute itself takes no institutional policy positions.

The Institute for the Study of Labor (IZA) in Bonn is a local and virtual international research center and a place of communication between science, politics and business. IZA is an independent nonprofit company supported by Deutsche Post World Net. The center is associated with the University of Bonn and offers a stimulating research environment through its research networks, research support, and visitors and doctoral programs. IZA engages in (i) original and internationally competitive research in all fields of labor economics, (ii) development of policy concepts, and (iii) dissemination of research results and concepts to the interested public.
\end{abstract}

IZA Discussion Papers often represent preliminary work and are circulated to encourage discussion. Citation of such a paper should account for its provisional character. A revised version may be available directly from the author. 


\section{ABSTRACT \\ Intrahousehold Specialization in Housework in the United States and Denmark}

Objective: Focusing on housework activities, we construct a gender neutral composite index measure of intrahousehold specialization. We hypothesize that the degree of specialization is influenced by economic notions of efficiency, as well as by time constraints and egalitarian values. Methods: Employing time use data on US and Danish couples, we model specialization using a multivariate two-limit Tobit. Results: We analyze the comparability of reported time use and our specialization index using different types of data. We find evidence that Danish households specialize less than American households and postulate that this cross-national difference is a result of the more egalitarian family culture within Scandinavia. A finding that children are associated with significantly increased specialization in the US but not in Denmark is attributed to the subsidized childcare services provided by the Danish welfare system. Conclusion: Intrahousehold specialization in housework varies with economic circumstances, time constraints, and social values.

JEL Classification: D13

Keywords: time use, housework, specialization

Corresponding author:

Leslie S. Stratton

Department of Economics

Virginia Commonwealth University

1015 Floyd Ave.

P.O. Box 844000

Richmond, VA 23284-4000

USA

E-mail: Isstratt@vcu.edu 


\section{Intrahousehold Specialization in Housework in the United States and Denmark}

A key advantage to multi-person households is their ability to benefit from specialization and the division of labor. A prominent example of such intrahousehold specialization is the 'traditional' household with a stay-at-home housewife and a career-focused husband. However, even in modern households and even within only the set of housework tasks specialization occurs, with one partner contributing substantial time to some tasks (like meal preparation) and the other partner contributing substantial time to others (like home maintenance). Here, we construct a gender neutral measure of intrahousehold specialization in housework that accounts for task-specificity and discuss how specialization by this measure may differ across couples with different abilities, needs, and values. Both economic and sociological theories motivate this discussion.

To analyze these theories we use time use data from the United States (US) and Denmark. We choose these countries because there has long been a contention that more egalitarian minded households allocate housework more evenly, and Denmark is reputed to be a more egalitarian society than the US. Our analysis indeed reveals that there is less specialization in Danish households. Even so, more detailed econometric analysis reveals substantial similarities in the relation between household characteristics and specialization within the US and Denmark. The most notable difference is the fact that children are associated with more specialization in the US but not in Denmark.

\section{Theory}

Specialization and the division of labor are touted by standard economics texts as fundamental principles of economics, because they allow production at the lowest possible cost. By dividing up tasks, less time and hence money is spent in task set-up. Learning by doing is also enhanced. Becker (1991) extended these principles to the analysis of households and argued that multiperson households have an advantage over single person households since they are able to 
take advantage of the benefits offered by specialization. His theory of marriage rests solidly on this premise, and though he focuses his discussion on the specialization of one partner in market and the other in household production, the notion of specialization can be applied far more broadly to explain intrahousehold time allocation.

There is evidence, for example, of significant specialization even within household production, as some tasks are female dominated and others male dominated (South and Spitze, 1994). Such a division of labor can be readily explained by economic theory. One prediction of this theory is that greater differences in the relative ability/skill of the partners will result in greater gains from specialization. ${ }^{1}$ Thus, more diverse couples may specialize more than less diverse couples. Examples are couples with diverse education backgrounds and couples with large age differentials. Such differences are indicative of skill differences not the least because they suggest differential labor market investments and therefore are predictors of specialization.

In a more formal model of intrahousehold specialization, Stratton (2005) posits that the degree of such specialization depends on the expected costs and benefits associated with specialization. The costs in this model are primarily the fixed costs associated with changing activities. The benefits are the increased provision of household goods made possible by specialization. Both the costs and the benefits may differ for households with different characteristics. For example, households with greater demands on their time or a greater value of time may benefit more from specialization. One measure of time value comes from the market. Hence, the market earnings potential of each partner as reflected in their age and education may be positively related to the degree of intrahousehold specialization. Another measure of time value comes from the home. The presence of children, and particularly pre-school aged children, by increasing the demands on time may increase the optimal degree of intrahousehold specialization. Children also increase the options for intrahousehold specialization as child care is an important task. Further, characteristics of the residence (rural/urban, type of home) may be correlated with household demands, the number of tasks to be performed, and specialization. 
Stratton (2005) argues that marital status and the duration of the relationship will be related to the degree of intrahousehold specialization as well. If there are costs associated with changing one's activities, then the longer the expected period of specialization, the lower will be the present value of the cost of changing tasks when the relationship ends and the greater will be the optimal degree of specialization. More enduring relationships should therefore be more specialized. Relationship type may also matter. In the US at least, married couples tend to be together longer than cohabiting couples and thus should be more specialized. In Denmark, the differences between married and cohabiting partnerships are less marked and so the relationship type is less likely to be associated with intrahousehold specialization (Kiernan, 2002).

There is also a substantial sociological literature in this area (Shelton and John, 1996, provide a review). In particular we focus on those theories that explain the division of household labor with reference to relative resources, time availability, or ideology. Both relative resource theory and time availability theory posit that housework is a necessary but undesirable task. Relative resource theory says that individuals with the most resources negotiate their way out of housework. This is akin to bargaining theory in economics which suggests that those household members with the most power will do less housework (Hersch and Stratton, 1994). Alternatively, the time availability approach posits that individuals are time constrained and that housework will be performed by the least time constrained party as flexibility is key. Ideological approaches focus on gender and emphasize the importance of individual beliefs regarding the role of men and women in couple households. One branch of this research suggests that housework is a means of 'constructing' or 'doing' gender and that women in particular derive pleasure out of being able to provide household services (see Bittman et al., 2003, for empirical evidence). Another branch suggests that couples who share more egalitarian views will naturally choose to divide tasks more evenly.

Here, we are not interested in knowing what fraction of housework women perform but rather how often housework tasks are completed by one individual rather than by both. In this case, the gendered notions of housework are not very relevant, but time constraints and egalitarian beliefs 
may be. Thus, while economic theory suggests that individuals who are more time constrained may have a greater incentive to specialize, time availability theory suggests that flexibility may be more important. The implication is that while economics suggests busy households will specialize more, time availability theory suggests they may specialize less. Those with egalitarian values may also specialize less. Fuwa (2004) argues that couples with more egalitarian values and those living in more egalitarian cultures tend to allocate time more equally to housework. Batalova and Cohen (2002) argue that cohabiting couples on average have more egalitarian values and find that they are more likely to share housework time. Hersch and Stratton (1994) and Shelton and John (1996) have used this theory to explain why more educated men contribute a greater share of household time to housework. One might also argue that younger 'more liberated' persons have more egalitarian values than older persons. Here the prediction for cohabiting couples and younger persons is similar using either economic or sociological approaches. Both are expected to be associated with less specialization. However, where a sociological emphasis on egalitarian values suggests a negative relation between specialization and education, economic theory suggests a positive relation based on time value considerations. Finally, our decision to analyze specialization in both the US and Denmark is driven in part by evidence (Fuwa, 2004) that the Danish culture is more egalitarian than the US culture. Thus our cross-country comparison gives us an opportunity to further explore (albeit indirectly) the impact of such values on time allocation decisions.

\section{Data}

Our analysis of intrahousehold specialization is primarily conducted using US data from the 1992-94 wave of the National Survey of Families and Households (NSFH) and Danish data from the 2001 Danish Time Use Survey (DTUS). In both cases we restrict the sample to heterosexual couple households. In the US we also eliminated couples in which either partner was enrolled in school fulltime, enlisted in the military, or over the age of 60 . In the case of the Danish data we eliminated all couples in which either partner was less than age 20 , over age 60 , or enrolled in school. Our initial samples consist of 4863 couples from the $\mathrm{NSFH}^{2}$ and 1326 from the DTUS. All estimates from the 
NSFH are weighted to adjust for the oversampling of recently married and cohabiting households, but the results from unweighted analysis are substantially similar. The Danish sample originates from a representative sample of the entire Danish adult population (16-74 years) drawn from the administrative registers at Statistics Denmark and as such is unweighted.

While we recognize that intrahousehold specialization may take place between the market and home spheres as well as in the home, due to sample size concerns, especially with the Danish data, we do not wish to limit our analysis by employment status, nor do we wish to jointly model market time allocations and intrahousehold specialization. Thus, ours is a reduced form specification as regards market-related measures of time value. We do, however, perform sensitivity testing by replicating the analysis for a sample of dual earner couples in the US, in order to ensure that the cross-country differences in intrahousehold specialization we observe are not attributable to the lower prevalence of dual earner couples in the US, and hence to differences in market/home specialization.

To measure and model the degree of intrahousehold specialization in housework in couple households requires fairly detailed information on housework time not just for one but for both partners. Yet the measurement of housework time is fraught with difficulties ${ }^{3}$, especially when using different types of time use data as is the case here.

The NSFH time use data are derived from questionnaires that ask each partner to report how much time they spend and how much time their partner spends on specific narrowly defined housework activities during an average week. Such retrospective questionnaire data appear sensitive to a number of issues. For example, one individual's reported time use may not be comparable with another's if different individuals perceive time differently and so have a different 'bias' to their questionnaire reporting. To minimize this individual-specific reporting bias, we construct our specialization measure using time use data provided by a single partner in the household for both. There is also evidence, particularly in the US, that responses can differ systematically by the gender of the respondent (Davis and Greenstein, 2004; Fuwa, 2004; Batalova and Cohen, 2002; Winkler, 2002; Lee and Waite, 2005). Generally, researchers have relied more 
heavily on questionnaire reports provided by women as there is some evidence that women provide more accurate estimates than men (Kan, 2006; Lee and Waite, 2005; Kamo, 2000). We therefore analyze the data as reported by men separately from the data as reported by women.

To construct our measure, we must have complete and credible reports on each of the relevant housework activities for both partners. ${ }^{4}$ A remarkably small fraction of our US households fail to provide the necessary information on housework from at least one partner. Married couples are somewhat more likely than cohabiting couples to report, but it seems likely that the cohabiting couples not captured are more often those experiencing troubles within their relationship so this bias is more likely to obscure differences between married and cohabiting households than to aggravate them. In sum we have time use data from 3675 households "as reported by women" and from 3559 households "as reported by men". We focus our analysis on the data reported by women in the text. Those for men are available upon request but are not substantially different.

The DTUS is relatively unique in providing two separate measures of housework time. One is based on questionnaire data that provide information not on the time spent on each housework task (time use questionnaires like those from the NSFH) but simply record who participates or contributes to each task (participatory questionnaires). The other data are time diary data that ask individuals to record all their activities during particular 24 hour periods.

The DTUS participatory questionnaire data are derived from the question, "Who does the following activities in your household?". Possible responses for each activity include: self, partner, both, and neither. No individual measures of time accompany these responses, though an aggregate measure of time spent on housework is included for each partner. As only the primary respondent completes these questionnaires, we again avoid individual-specific reporting bias. In the case of the Danish data there is no evidence of gender-specific bias. Overall, all but eight households completed this questionnaire, yielding a sample of 1318 Danish households providing the participatory type data.

Time diaries were administered at the same time the DTUS questionnaire was delivered. The diary data consist of both a weekday and a weekend day diary for each partner within the 
household. Respondents report the starting and ending times of each activity in 10 minute intervals throughout a 24 hour period. The activity questions are open-ended, the respondent being asked to use his/her own wording. These descriptions are then coded into standardized activities following the recommendations for European time-use surveys (Eurostat, 2000). Secondary time use activities, such as doing laundry while watching the children, could also be recorded. We consider a diary to be complete if activities are recorded for at least 23 of 24 hours. By this measure 711 households provide a complete set of four time diaries.

While time use differences can arise due to the reporting method, they can also arise due to differences in the definition of housework. The activities that constitute 'housework' are often not clearly delineated. Such is not the case here. The NSFH data measure the time spent on a weekly basis by each partner on a quite comprehensive set of nine different housework activities: Meal Preparation, Dishes, Cleaning, Laundry, Shopping, Outdoor Maintenance, Auto Repair, Paying Bills, and Driving Others. The activities for which participation is recorded in the Danish questionnaires are Meal Preparation, Dishes, Cleaning, Laundry, Shopping, Gardening, House Maintenance, Driving to School/Day Care, Picking up from School/Day Care, and Driving Children to/from other activities. The Danish time diaries report time spent on Meal Preparation, Dishes, Cleaning the Residence, Laundry, Ironing and Mending, Shopping, Gardening, Construction and Repairs, and Driving a Child. To more closely match the "outdoor maintenance" activity from the NSFH, we combine the gardening and home maintenance activities from the Danish data. Likewise the three activities involving transportation are combined from the participatory Danish data in order to match "driving others" and "driving a child" from the NSFH and Danish time use samples, and laundry and ironing are combined from the Danish time use data in order to match "laundry" from the other sources. As the Danish data do not include information on auto repair or paying bills, information on these activities is excluded from the housework specialization measure we construct. As auto repair is more often a hobby and paying bills typically takes very little time ${ }^{5}$, excluding these tasks does little to undermine the comprehensiveness of our housework measure. In general, the DTUS and NSFH activity classifications are relatively clearly defined, comparable in scope, and quite 
comprehensive, leaving seven comparable housework tasks for the analyses: Meal Preparation, Dishes, Cleaning, Laundry, Shopping, Outdoor Maintenance, and Driving Others.

\section{Intrahousehold Specialization}

\section{Definition}

Specialization occurs when household members divide up tasks and individually allocate their time to only a subset of activities, rather than divide their time more evenly across all tasks. Aggregating time spent across tasks to construct a single share measure will understate the degree of intrahousehold specialization if different individuals perform different household tasks. A few studies model the share of time contributed by one individual task by task (Twiggs, McQuillan, and Ferree, 1999), but face the problem that all these task-specific decisions must be jointly determined. Still others construct a single composite measure that tries to account for specialization by task as well as heterogeneity across households in the allocation of tasks (Blair and Lichter, 1991; Stratton, 2005).

We take the latter approach and construct a composite index of intrahousehold specialization in housework that takes a value of zero when there is no intrahousehold specialization in the seven housework tasks we observe and a value of one when there is complete intrahousehold specialization. Hence, a value of zero means that each individual contributes (equally where measured) to each task, and a value of one means that each task is performed by only one partner. Where the amount of time spent is reported, the tasks are weighted by the amount of time spent and the index value is equivalent to a measure of the degree to which household housework time would have to be increased to achieve equal sharing (thus a value of one implies that the household would have to double its housework time with the nonparticipating partner adding equal time to the participating partner on each activity).

In the case of the NSFH and of the DTUS Diary Data, the Specialization Index has the following form: 


$$
S I=\left[\frac{\sum_{i=1}^{7} \operatorname{Max}\left(H W_{i}^{M}, H W_{i}^{F}\right)}{\sum_{i=1}^{7}\left(H W_{i}^{M}+H W_{i}^{F}\right)}-0.5\right] \times 2
$$

where $\mathrm{HW}_{\mathrm{i}}^{\mathrm{M}}$ and $\mathrm{HW}_{\mathrm{i}}^{\mathrm{F}}$ indicate the time spent on housework task $i$ by men and women respectively. The NSFH provides information on usual weekly time for each partner, while the DTUS diary data provide information on both weekday and weekend days for each respondent. We use a weighted sum of these diaries that assigns a weight of five to the weekday and a weight of two to the weekend surveys. The numerical adjustments in the index simply scale the index to fall between zero and one.

The intrahousehold specialization measure calculated using the DTUS questionnaire data on participation is somewhat more limited in nature. The numerator takes a value of one for those single activity tasks ("meal preparation", "dishes", "cleaning", "laundry", and "shopping") that the respondent indicates are performed by only one partner, else zero. An average value of specialization is constructed across activities when a task comprises more than one activity ("outdoor maintenance" and "driving others"). The denominator consists of the number of different tasks that are performed within the household. Because $\mathrm{HW}_{\mathrm{i}}$ has only a small number of possible values, the Specialization Index constructed from the participatory data is not as 'smooth' as those constructed from the NSFH or from the DTUS Time Diary data.

\section{Expectations}

This measure of intrahousehold specialization is likely to differ in predictable ways with the type of time use data. The simple participatory information available in the Danish questionnaire data differs in two ways from the time use information available in the US questionnaire data. First, the participatory-based measure weights each activity equally and second, it captures only extreme levels of participation. If both partners spend some time on an activity, no matter how unbalanced that time is, the bias will be for the participatory measure to report shared activity and hence to understate specialization. Likewise, if there is more specialization in those activities that take more 
time, but tasks are combined using equal weights, then the aggregation process will impart a further downward bias in specialization. ${ }^{6}$ We are able to identify the magnitude of these biases by constructing participatory-like measures using the NSFH data and comparing these to the questionnaire-based NSFH measure.

In general, time diary methods are believed to provide a more accurate accounting of time spent than any type of questionnaire data (Robinson, 1985). However, time diary records only capture those activities performed during the period for which the diary is collected. Not all housework activities will be captured and the data may not be representative of an average day. Moreover, diary data will capture both specialization by task and specialization by day. Each individual in a household may spend the same amount of time doing dishes in an average week, but the partners may specialize by doing dishes on alternate days and the diaries only capture a subset of those days. The longer the period for which diary data are reported, the more representative the diary data are likely to be and the more accurate will be the resulting specialization measures. Because we only observe a limited number of days, we believe our diary data will generally overstate specialization. As we have two complete diaries for each partner, we can partially assess the magnitude of this bias by comparing specialization indices constructed using one as compared with two day diaries.

Comparisons of questionnaire and time diary data on time use suggest that relative to time diary data, questionnaire data overstate all time spent (Robinson, 1985; Shelton and John, 1996; and Lee and Waite, 2005) or overstate time spent on frequent but understate time spent on infrequent activities (Bonke, 2005), and that this differential is generally greater for housework time than for paid work. One reason given for this differential is that housework tasks are often performed as a secondary activity (Robinson, 1985; Kitteroed, 2001; Floro and Miles, 2003; Lee and Waite, 2005). ${ }^{7}$ Questionnaire-based measures of time use may incorporate this secondary time, while primary time diary records do not. How these differences may bias measures of specialization is uncertain. We compare a specialization index calculated using only primary diary data with one calculated using both primary and secondary diary data in an effort to see how sensitive our diary- 
based index is to the inclusion of secondary time diary data. To ascertain how the index measure differs using questionnaire-based versus time diary-based data, we compare the DTUS questionnaire data with the DTUS time diary data for Denmark.

Finally, we recognize that intrahousehold specialization may change over time. As the US data were collected in 1992-94 and the Danish data in 2001, cross-country differentials between these data could be attributed to changes over time in specialization. We explore this possibility by examining time diary data from the 1987 Danish Time Use survey, the 1985 AUT, and the 2003 American Time Use Survey (ATUS).

\section{Evidence}

Our notation identifies the specialization indices (SI) with a $\mathrm{Q}$ for their questionnaire-based and a D for their diary-based origins. The initials US and DK identify the national samples. The US values are as reported by women, but we abstain from noting this explicitly in the variable names. We distinguish between time use questionnaires and participatory questionnaires by appending a $\mathrm{T}$ for "time use" and a "P" for "participatory". Thus, the variable name US SIQT indicates the US questionnaire-based specialization index as calculated from women's reports using the measures of time use. Table 1 provides summary statistics for all our primary SI measures.

Comparing the questionnaire-based indices: participatory versus time use measures. The questionnaire-based specialization indices are substantially different as can be seen by examining the first and third columns of Table 1. The US measure that uses the time reports (US SIQT) has a mean value (0.62) that is almost twice that obtained from the participatory Danish data (DK SIQP 0.35). This difference is clearly reflected in the distributional analysis. Fewer than $5 \%$ of the US sample reports less than $20 \%$ specialization, as compared to almost $40 \%$ of the Danish sample. Conversely, $26 \%$ of US households have an index value of at least 0.80 versus $4 \%$ of the Danish households.

*** Table 1 about here $\quad * * *$ 
To explore how much of this differential is driven by differences between the participatoryand time use-based questionnaires, we have constructed a modified US index that mimics the Danish data by characterizing any time spent by a partner on an activity as participation and by weighting each of the seven activities equally. While still indicating more specialization in the US, the resulting US specialization index (US SIQP) is substantially closer to the Danish index value in terms of mean ( 0.44 versus 0.35$)$ and distribution. Further analysis (not shown in the table) indicates that it is the availability of only a simple participatory response not the equal weighting of activities that drives the explained differential. When the task weights are equal, but the participatory responses more detailed, the mean US specialization index value is 0.636 or slightly higher than that observed with non-equal weights. When the task weights are allowed to be a function of household time but the participatory responses for each of the seven activities are forced to take extreme $0 / 1$ values, the mean US specialization index value falls to 0.369 . When the task weights are forced to be equal and specialization is defined as contributing $80 \%$ or more of the household time towards a particular activity, thus relaxing the assumption of all or nothing specialization, the resulting index has a mean value of 0.591 , almost equivalent to the fully time use-based questionnaire measure, suggesting that our US SIQP measure is more likely to under than to overstate specialization relative to the DK SIQP measure.

The cross-country differential that remains using analogous specialization measures (US SIQP versus DK SIQP) is substantial. The mean specialization index value using participatory data is $25 \%$ higher in the US and the fraction of households that are highly specialized (index value of 0.80 or higher) in the US is three to four times greater than in Denmark. The fact that a greater fraction of US households report $100 \%$ specialization (7\%) than the fraction of Danish households reporting an index value of 0.8 or higher (3.8\%) also provides evidence of greater intrahousehold specialization within the US.

An analysis of the US time use data as reported by men yields similar but less striking results. Men in the US report spending more time on housework than their partners report them spending and so when the US specialization index is constructed using men's time reports, it has a 
lower value: the Male US SIQT is 0.56 versus 0.62 for the Female US SIQT. Still, the fraction of US men reporting complete (100\%) specialization is the same as the fraction of Danes reporting specialization of 0.8 or higher: $4 \%$. Even though men in the US report less intrahousehold specialization than women in the US, there is still evidence that the Danes specialize less.

One explanation for the cross-country differences could be the greater variance in household employment status within the US as compared to within Denmark. It may be that US couples are more likely to specialize not only at the home, but also between the market and the home. We examine this possibility by calculating the index value for those US households in which both partners are employed in the market. The index is smaller for this sample (the US SIQP equivalent is 0.40 ), but still over $15 \%$ larger than that observed in Denmark.

Comparing the Danish time diary and participatory measures. The Danish diary data provide the activity-specific time use measurements that are missing from the Danish participatory questionnaire data, however, they are based on only a particular 48 hours rather than a 'normal' seven day week. For this reason the specialization indices calculated from these two sources may not be directly comparable. In total, there are 1318 households for whom the questionnaire-based index and 711 households for whom both the questionnaire and the diary-based indices can be calculated. Differences in the indices calculated off the 711 household sample must be attributed to differences in data type rather than to differences in sample composition. The final three columns of Table 1 present summary information for each of these three samples/indices.

The third and fourth columns present summary statistics for the questionnaire-based index from the full sample and the diary sample. There are no substantial differences between the samples in either the mean or the distribution of the index and the differences by other characteristics are modest at best between these samples and not significant at the $5 \%$ level. This table presents no evidence that sample selection is an issue in the reporting of the diary data, nor is there evidence of a gender-based reporting bias. By contrast, there are substantial differences between the index as calculated from the questionnaire data and the index as calculated from the 
diary data, as indicated by a comparison of columns four and five in Table 1. The diary-based measure (DK SIDT) indicates 62.8\% specialization, whereas the questionnaire-based measure (DK SIQP) indicates only $34.8 \%$ specialization. Whereas only about $4 \%$ of the households are highly specialized (> 80\%) as measured using the questionnaire data, over $20 \%$ are using the time diary data.

One reason for the different specialization index values is that time diary data cover a shorter time spell (48 hours) than the questionnaire data (1 week). This is reflected in the number of distinct housework activities for which time is reportedly spent. Of the seven activities reflected in our specialization measure, an average of 5.4 activities is reported in the diary data as compared with 6.3 in the questionnaire data. How this might impact the specialization measure depends upon what tasks are missed and the specialization of these tasks. In addition, the shorter observation period means that time diaries capture not just specialization by task but also specialization by day, which probably overstates specialization. An examination of the index as calculated using a single day diary helps gauge the impact a longer diary has upon the specialization index. We find the index value rises to 0.72 for weekdays ( 0.69 for weekends) when using only a 24 hour diary. Thus, a doubling of the diary period is associated with a $10 \%$ drop in the value of the specialization index. This result suggests that the index is indeed biased upward as a result of the short nature of the sample period.

Another difference may arise if housework is reported as the secondary rather than the primary activity in the time diary data. We examine this possibility by constructing a measure of intrahousehold specialization using diary data on both primary and secondary time use (results available upon request). Both the time spent on housework and the number of different tasks reported increase ( $5 \%$ and $2 \%$ respectively), but the average specialization index does not substantially change, going from 0.63 to 0.62 . Time diary measures of specialization are much more sensitive to the number of diary days than to the primary/secondary classification of activities.

Overall, the evidence from the Danish data is that time diary-based measures of specialization are substantially higher than participatory measures of specialization and likely 
overstate true specialization. ${ }^{8}$ Since we expect the DK SIDT value to overstate specialization in Denmark, the finding that it is of about the same magnitude as the US SIQT measure provides further evidence that there is more specialization in the US than in Denmark.

Comparing Danish and US indices by type of data and over time. There remains some concern that the higher rates of specialization we observe within the US as compared to Denmark could be the result of the date at which the data were collected. The DTUS data come from a survey administered in 2001 while the NSFH data come from a survey administered in 1992-94. How specialization might have changed over time is not clear. We examine this issue by using time diary data from the 1985 AUT and the 2003 ATUS in the US and from the 1987 and 2001 DTU surveys in Denmark. These surveys clearly demonstrate that less time is now spent on housework. Time spent per week per couple on these seven activities declined from 34 to 29 hours in the US. The Danish measures fell even more dramatically from 31 to 16 hours. This dramatic change in time use, however, need not also reflect a change in intrahousehold specialization. Unfortunately, neither the 2003 ATUS nor the 1987 DTUS provides information on the time use of both partners. Thus, we construct a makeshift measure of intrahousehold specialization for each of these samples using the sample average time partners spend on each of the seven housework activities. These measures are reported in Table 2 and are surprisingly close to though generally slightly below what we observe for the matched partner data we have from the 1985 AUT and the 2001 DTU surveys. They indicate that there has been very little change in the US over these 20 years, but perhaps a small decrease in specialization in Denmark. In each decade, however, specialization is consistently greater in the US than in Denmark.

*** Table 2 about here $\quad * \star *$

\section{Multivariate Analysis}

We proceed now to a multivariate analysis of intrahousehold specialization in housework in order to determine the degree to which economic and/or sociological theories can explain differences in specialization. As the specialization index is designed to run from zero to one and 
clearly has some massing at the extreme values, we employ a two-limit Tobit specification in our analysis.

The covariates include information on the total number of hours spent weekly on housework by both partners, the number of different housework tasks performed, the man's level of age and education, the difference between the man's age and education and that of his partner ${ }^{9}$, and an indicator variable to identify married couples. Ideally we would control for the expected duration of the relationship, but we have only information on the completed duration which we enter in quadratic form. The duration measures are self-reported (but cross-checked against partner reports) in the US data and obtained from annual Danish register data, which go back to 1980 . Relationship duration is truncated for Danish couples formed before 1980. Those observations with truncated values are identified with a dummy variable. As the benefits associated with duration are predicted to rise at a decreasing rate, it is unlikely this restriction will substantially bias our results. Indicator variables are also included to identify households with one child, with two or more children, and with at least one child younger than school age (six in the US and seven in Denmark). We include a dummy to identify those households residing in single family dwellings as compared to generally smaller apartments, because of the different tasks to be performed. We also control for residence in an urban area (SMSA in the US, Copenhagen in the Danish sample) in order to control for easier access to purchased alternatives to household labor than in rural areas. Additional controls for region of residence and race are incorporated in the US analysis.

Sample means (and standard deviations) for those variables defined comparably across the samples are presented in Table 3. Full results are available upon request. The first two columns present statistics for the US questionnaire data. The second two columns show statistics for the questionnaire-based Danish sample and the last two columns show statistics for the diary-based Danish sample.

*** Table 3 about here 
The table reveals substantial differences between the countries. Within the US sample, only about $7 \%$ of the couples are cohabiting relative to about $25 \%$ in the Danish samples. While Years in Relationship appears larger for the US sample, this is largely the result of truncation at 22 years in the Danish data. When a similar constraint is imposed on the US sample, Years in Relationship for that sample declines. While about one-third of the Danish sample has been in a relationship for over 21 years, this is true for only about $28 \%$ of the US sample. Thus, relationships appear to be somewhat more enduring in Denmark as well as less likely to involve formal marriage. Time spent on housework differs markedly cross-country. American couples report spending almost 43 hours a week on the seven housework activities measured here. Danish couples report spending about onethird less time at these chores. ${ }^{10}$ This is true even when comparing the 2003 ATUS diary data to the 2001 DTUS and is rather surprising as the greater tax burden imposed on market purchases in Denmark would suggest that Danes should spend more not less time on housework than Americans. Higher tax rates increase the cost of purchasing substitutes relative to performing the task in house. Furthermore, Danes are more likely to live in a single family dwelling and less likely to have more than two children - though not less likely to have children who are not yet in school. US men are somewhat younger and have more years of schooling than their Danish counterparts. In both Denmark and the US, women are about two years younger than their partners. While the difference is small, it is interesting to note that in the US, women are a little less well educated while in Denmark they are a bit better educated than their partners.

$\star \star \star \quad$ Table 4 about here $\quad * \star \star$

Table 4 presents coefficient estimates from the two-limit Tobit model of intrahousehold specialization. The questionnaire-based results (columns 1 and 2) are remarkably similar crosscountry. Longer relationships are associated with greater intrahousehold specialization albeit with diminishing returns in all specifications. This result is as predicted by economic theory assuming that current duration is a reasonable proxy for expected duration. Indeed, the fact that shorter relationships are more heterogeneous (because they include both relationships that will be short- 
lived and relationships that will be long-lived) suggests that the impact of relationship duration may be understated here. The magnitude of the duration measure is similar across countries in a linear specification, but appears to have greater diminishing returns in Denmark. The coefficient to the dummy variable identifying households for whom the duration of the relationship is over 22 years does have a positive sign for the Danish sample, but is not statistically significant.

Other results also support an economic interpretation. That households with older men engage in more specialization could be driven by economics and market value of time considerations. Likewise, our finding that the lower the woman's education relative to her partner's supports the economic hypothesis that the benefits to specialization rise with skill differentials. Other results, however, are more supportive of sociological theories. Households with more educated men are significantly less specialized. This result as well as the finding that Danish households are more specialized than US households suggests (albeit indirectly) that social norms and egalitarian views are important. Likewise the finding that households that spend more time on housework and perform more household tasks are less specialized is more supportive of a time availability notion than of the economic notion that more time constraints make specialization more valuable. Couples with more housework to complete in a given period of time appear to rely more on flexibility and hence be less specialized when allocating housework tasks. While marital status and residence in a single family dwelling are typically associated with greater intrahousehold specialization in a simple univariate analysis, neither of these factors is statistically significant in the multivariate analysis.

One finding from the questionnaire-based data that differs cross-country is the impact of children on household specialization. Children do not have a significant impact on specialization in Denmark (a joint F-test of the three variables yields a p-value of 0.62), but do in the US (p-value 0.00). The presence of children, particularly young children, is associated with a large increase in intrahousehold specialization in the US. ${ }^{11}$ Results using the participatory measure (US SIQP), using the data as reported by men, and restricting the sample to dual earner couples are substantially the same (available upon request). 
To explore the possibility that, as suggested by Batalova and Cohen (2002), there may be differences between married couples who initially cohabited and married couples who did not, we estimated a model incorporating this distinction (results not shown) for the US. We find that married couples who initially cohabited behave like currently cohabiting couples, while married couples who did not initially cohabit are marginally ( $p$-value 0.14 ) more likely to specialize. This finding is akin to Batalova and Cohen's and lends further support to the hypothesis that relationship type/egalitarian values are an important determinant of intrahousehold specialization.

When using the diary-based measure of intrahousehold specialization the results are quite different from those obtained using questionnaire-based measures. For example, using questionnaire data marital status had no significant or a slightly positive association with specialization; using time diary data marital status has a significant negative relation to specialization. Individuals in longer lasting relationships appeared to be more specialized using questionnaire data, but not significantly so using time diary data. Households spending more time on housework reported less specialization using questionnaire data and more using time diary data. These significant changes may indicate a difference in the reporting of diary- and questionnairebased data. They are not attributable to differences in the sample alone, as results using the questionnaire-based measure of intrahousehold specialization for the diary sample are substantially the same as those reported here for the full questionnaire sample. Nor do these differences appear attributable to sample selection bias. Given the substantial sample reduction, we did test for sample selection bias, instrumenting for survey completion using measures of household income and stress. Our results are similar to those reported by Abraham, Maitland, and Bianchi (2005) for the American Time Use survey and Bonke (2002) for this sample. Higher income households are more likely to complete the diaries, but our estimates of the specialization index model are unchanged. Finally, we find that our time diary results are robust to an alternative definition of the index value that uses both primary and secondary time diary reports. ${ }^{12}$

\section{Discussion and Conclusion}


We used data on a comprehensive set of seven household tasks gathered from couples in the US and Denmark to construct measures of intrahousehold specialization in housework. The US data come from the 1992-94 wave of the National Survey of Families and Households and provide relatively detailed questionnaire data on time use, while the Danish data come from the 2001 Danish Time Use survey and provide both barebones questionnaire data on participation as well as detailed 48 hour time diary information. We show that the precise level of specialization differs systematically based on the type of time use data used. Specifically, questionnaire data on participation yielded lower estimates of specialization than more detailed questionnaire data, probably because only very specialized households report nonparticipation. By contrast time diary-based data provided the highest estimates of specialization, perhaps because they capture not only specialization by task but also by day. Despite the differences in our data, we found substantial evidence that there is more intrahousehold specialization in the US than in Denmark and no evidence that this difference is attributable to the almost decade later collection of the Danish data.

We then conducted a multivariate analysis of intrahousehold specialization using a variety of variables suggested by either economic or sociological theory. Economic theory suggests that the degree of intrahousehold specialization in housework will be a function of the costs and benefits associated with such specialization. The benefits are likely to be greater the more time constrained the household and the greater the intrahousehold division of skills (the greater the potential comparative advantages). The costs are likely to be lower the more enduring the relationship. Countering this economic perspective is the evidence from sociology that individuals in more time constrained households and in more egalitarian-oriented households may favor more flexible or more equal divisions of chores and so exhibit less intrahousehold specialization.

Our results using the questionnaire-based data from both countries show remarkable similarity. Older couples, those in more enduring relationships, and those with more disparate education levels were found to specialize more, supporting economic theory. However, households with more tasks to perform and more household time devoted to those tasks specialized less. This finding suggests that such households value the flexibility offered when both partners have the skills 
to perform the tasks more than the advantages inherent in specialization. Finally, there was evidence from both countries that younger and more educated couples specialize less. These results provide substantial, albeit indirect, evidence that egalitarian values are an important factor in intrahousehold time allocation and reduce specialization. Substantial differences in social norms regarding egalitarianism may also explain the cross-country differences in specialization. The more egalitarian-minded Danes (as evidenced by their social welfare policies and in sociological research [Fuwa, 2004]) may specialize less for cultural reasons.

One key distinction we observed between Denmark and the US was in the impact of children on intrahousehold specialization. Children did not appear to have any impact on specialization in Denmark, whereas children (particularly young children) were associated with increased specialization in American households. We believe these cross-country differences are attributable to the substantial cross-country differences in the availability of affordable, high quality day care. The Danish social welfare system provides subsidized childcare services that are only available at high cost in the private sector in the US. Thus, the impact of children on households is likely greater in the US than in Denmark.

Finally, a comparison of the multivariate model of intrahousehold specialization using questionnaire- versus time diary-based data from the same sample of Danish households revealed tantalizing differences. While the presence of children continued to have no significant effect and the education level of the respondents continued to have a significant dampening effect on intrahousehold specialization, a number of factors had an effect that differed significantly depending upon the type of data used to calculate intrahousehold specialization. Specifically, while Years in Relationship was positively related to specialization using the questionnaire-based data, it was marital status that was significant but negatively related to specialization using diary-based data. This result suggests that married and cohabiting couples may respond differently when asked about household tasks than when asked to report on their own time use. In addition, the questionnairebased analysis revealed that households spending more time on housework specialized less, whereas the diary-based analysis reveals just the opposite. This finding lends some support to our 
proposition that busier households may find specialization by tasks too confining - but may still specialize by day as indicated in the time diary analysis. Overall, we find evidence that intrahousehold specialization in housework varies both within and between countries depending upon economic circumstances, time constraints, and social values. 


\section{REFERENCES}

Abraham, Katharine G., Aaron Maitland, and Suzanne Bianchi. 2006. "Nonresponse in the American Time Use Survey: Who is Missing from the Data and How Much Does It Matter?" Public Opinion Quarterly 70(5): 676-703.

Batalova, Jeanne A. and Philip N. Cohen. 2002. "Premarital Cohabitation and Housework: Couples in Cross-National Perspective." Journal of Marriage and Family 64: 743-755.

Becker, Gary S. 1991. A Treatise on the Family. Enl. ed. Cambridge, Mass.: Harvard University Press.

Bittman, Michael, Paula England, Nancy Folbre, L. Sayer, and G. Matheson. 2003. "When does gender trump money: Bargaining and time in household work, American Journal of Sociology 109(1), 186-214.

Blair, Sampson Lee and Daniel T. Lichter. 1991. "Measuring the Division of Household Labor: Gender Segregation of Housework Among American Couples." Journal of Family Issues 12: 91-113. Bonke, Jens. 2002. Tid og velfærd. (Time and Welfare). The Danish National Institute of Social Research. Report 02:26.

Bonke, Jens. 2005. "Paid Work and Unpaid Work: Diary Information versus Questionnaire Information." Social Indicator Research 70: 349-368.

Davis, Shannon N. and Theodore N. Greenstein. 2004. "Cross-national Variations in the Division of Household Labor." Journal of Marriage and Family 66 (5): 1260-1271.

Eurostat. 2000. Guidelines on Harmonised European Time Use Surveys. European Commission \& Eurostat. Luxembourg.

Floro, Maria Sagrario and Marjorie Miles. 2003. "Time Use, Work and Overlapping Activities:

Evidence from Australia." Cambridge Journal of Economics 27(6): 881-904.

Fuwa, Makiko. 2004. "Macro-Level Gender Inequality and the Division of Household Labor in 22

Countries." American Sociological Review 26: 751-767.

Hersch, Joni and Leslie S. Stratton. 1994. "Housework, Wages, and the Division of Housework Time for Employed Spouses." American Economic Review 84(2): 120-125. 
Kamo, Yoshinori. 2000. ''He Said, She Said': Assessing Discrepancies in Husbands' and Wives' Reports on the Division of Household Labor." Social Science Research 29: 459-476.

Kan, Man Yee. 2006. "Measuring Housework Participation: The Gap between 'Stylised'

Questionnaire Estimates and Diary-based Estimates." ISER Working Paper No. 2006-11.

Kiernan, Kathleen. 2002. "Cohabitation in Western Europe: Trends, Issues and Implications." Eds.

Ann Crouter and Allan Booth: Just living Together. Implications of Cohabitation on Families, Children and Social Policy. Mahwah, New Jersey: Earlbaum: 3-31.

Kitteroed, R.H. 2001. "Does the recording of parallel activities in Time Use Diaries affect the way people report their main activities?" Social Indicators Research 56(2): 145-178.

Lee, Yun-Suk and Linda J. Waite. 2005. "Husbands' and Wives' Time Spent on Housework: A Comparison of Measures." Journal of Marriage and Family 67: 328-336.

Robinson, John P. 1985. "The Validity and Reliability of Diaries versus Alternative Time Use Measures." Pp. 33-62 in F. T. Juster and F. P. Stafford, eds., Time, Goods, and Well-Being. Ann Arbor, Michigan: Survey Research Center, Institute for Social Research, University of Michigan. Shelton, Beth Anne and Daphne John. 1996. "The Division of Household Labor." Annual Review of Sociology 22: 299-322.

South, Scott J. and Glenna Spitze. 1994. "Housework in Marital and Non-Marital Households." American Sociological Review 59: 327-347.

Stratton, Leslie S. 2005. Specialization in Household Activities within Cohabiting versus Married Households. Paper presented at the Society of Labor Economics meetings in San Francisco. Twiggs, Joan E., Julia McQuillan, and Myra Marx Ferree. 1999. "Meaning and Measurement: Reconceptualizing Measures of the Division of Household Labor." Journal of Marriage and the Family 61: 712-724.

Winkler, Anne E. 2002. "Measuring Time Use in Households with More than One Person." Monthly Labor Review 125(2): 45-52. 


\begin{tabular}{|c|c|c|c|c|c|}
\hline \multicolumn{6}{|c|}{$\begin{array}{l}\qquad \text { Specialization Index Values } \\
\text { From US Questionnaire and Danish Questionnaire and Diary Data }\end{array}$} \\
\hline & $\mathrm{US} \mathrm{SIQT}^{\mathrm{a}}$ & US SIQP & DK SIQP ${ }^{a}$ & DK SIQP ${ }^{a}$ & $\mathrm{DK} \mathrm{SIDT}^{\mathrm{a}}$ \\
\hline Full Sample Mean & 0.623 & 0.438 & 0.349 & 0.348 & 0.628 \\
\hline \multicolumn{6}{|c|}{ Distributional Analysis } \\
\hline $0.00-0.19$ & $4.76 \%$ & $28.11 \%$ & $39.23 \%$ & $39.80 \%$ & $1.55 \%$ \\
\hline $0.20-0.39$ & $14.07 \%$ & $19.32 \%$ & $27.85 \%$ & $27.29 \%$ & $14.49 \%$ \\
\hline $0.40-0.59$ & $24.84 \%$ & $23.43 \%$ & $16.54 \%$ & $16.32 \%$ & $29.96 \%$ \\
\hline $0.60-0.79$ & $29.90 \%$ & $12.05 \%$ & $12.59 \%$ & $12.94 \%$ & $30.94 \%$ \\
\hline $0.80-1.00$ & $26.42 \%$ & $17.09 \%$ & $3.79 \%$ & $3.66 \%$ & $23.07 \%$ \\
\hline \# of Observations & 3675 & 3675 & 1318 & 711 & 711 \\
\hline
\end{tabular}

\begin{tabular}{|c|c|c|c|c|}
\hline \multicolumn{5}{|c|}{$\begin{array}{c}\text { Table } 2 \\
\text { Diary-Based Specialization Index Values }\end{array}$} \\
\hline & US S & amples & Danish & Samples \\
\hline Data Set: & 1985 AUT & 2003 ATUS & 1987 DTUS & 2001 DTUS \\
\hline Weekday & 0.789 & 0.776 & 0.727 & 0.680 \\
\hline Weekend Day & 0.735 & 0.725 & 0.698 & 0.654 \\
\hline
\end{tabular}




\begin{tabular}{|c|c|c|c|c|c|c|c|}
\hline \multicolumn{8}{|c|}{ Table 3} \\
\hline \multicolumn{8}{|c|}{ Sample Statistics } \\
\hline & \multicolumn{2}{|c|}{$\begin{array}{c}\text { US Questionnaire } \\
\text { Data }\end{array}$} & \multicolumn{2}{|c|}{\begin{tabular}{|c|} 
DK Questionnaire \\
Data
\end{tabular}} & \multicolumn{2}{|c|}{ DK Diary Data } & \\
\hline & \multicolumn{2}{|c|}{$\underline{\mathrm{US} \mathrm{SIQT}}^{\underline{b}}$} & \multicolumn{2}{|c|}{$\underline{\mathrm{DK}} \mathrm{SIQP}^{\underline{b}}$} & \multicolumn{2}{|c|}{$\underline{\mathrm{DK} \mathrm{SIDT}}^{\underline{b}}$} & \\
\hline Variable & $\underline{\text { Mean }}$ & Std. Dev. & Mean & Std. Dev. & $\underline{\text { Mean }}$ & Std. Dev. & $\begin{array}{l}\text { Differ- } \\
\text { ences }^{\mathrm{c}}\end{array}$ \\
\hline Questionnaire-based Specialization Index & 0.623 & 0.236 & 0.349 & 0.249 & 0.348 & 0.249 & $x, y$ \\
\hline Diary-based Specialization Index & & & & & 0.628 & 0.215 & \\
\hline Married & 0.929 & 0.257 & 0.736 & 0.441 & 0.754 & 0.431 & $x, y$ \\
\hline Years in Relationship & 15.032 & 10.146 & 13.250 & 7.790 & 13.585 & 7.716 & $\mathrm{x}, \mathrm{y}$ \\
\hline Dummy for Truncated Duration Measure & & & 0.322 & 0.467 & 0.340 & 0.474 & \\
\hline Hours per Week Couple Spends on Housework & 42.523 & 18.669 & 27.281 & 15.335 & 27.717 & 15.723 & $x, y$ \\
\hline - Diary-Based & & & & & 28.663 & 13.865 & \\
\hline \# of Housework Activities Reported & 6.463 & 0.663 & 6.313 & 0.587 & 6.304 & 0.567 & $\mathrm{x}, \mathrm{y}$ \\
\hline - Diary-Based & & & & & 5.366 & 1.126 & \\
\hline Living in a Single Family Dwelling & 0.743 & 0.437 & 0.826 & 0.379 & 0.844 & 0.363 & $x, y$ \\
\hline Dummy for 1 Child in Household & 0.214 & 0.410 & 0.213 & 0.409 & 0.213 & 0.410 & \\
\hline Dummy for 2+ Children in Household & 0.416 & 0.493 & 0.347 & 0.476 & 0.331 & 0.471 & $\mathrm{x}, \mathrm{y}$ \\
\hline Dummy for Child Younger than School Age & 0.280 & 0.449 & 0.299 & 0.458 & 0.273 & 0.446 & \\
\hline Man's Age & 41.510 & 9.344 & 42.884 & 10.069 & 43.790 & 9.978 & $\mathrm{x}, \mathrm{y}$ \\
\hline Man's Age - Woman's Age & 2.185 & 4.294 & 2.184 & 4.254 & 2.283 & 4.335 & \\
\hline Man's Years of Education & 13.738 & 2.890 & 12.583 & 2.754 & 12.848 & 2.709 & $\mathrm{x}, \mathrm{y}, \mathrm{z}$ \\
\hline Man's Education - Woman's Education & 0.247 & 2.437 & -0.097 & 2.853 & -0.101 & 2.839 & $\mathrm{x}, \mathrm{y}$ \\
\hline Number of Observations & 3675 & & 1318 & & 711 & & \\
\hline b: SI = Specialization Index, Q = Questionnaire da & $D=$ Diary & data, $T=1$ & Time use & data, $P=P_{c}$ & articipato & ry data. & \\
\hline $\begin{array}{l}\text { C: Indication of statistical significance at the } 5 \% \text { leve } \\
\text { SIQP and DK SIDT. }\end{array}$ & $\overline{\text { Neen: }>}$ & US SIC & and $D$ & IQP, $y=$ & $\overline{S \text { SIQT }}$ & nd DK S & $\mathrm{DT}, \mathrm{z}=\mathrm{DK}$ \\
\hline
\end{tabular}




\begin{tabular}{|c|c|c|c|c|c|c|}
\hline \multicolumn{7}{|c|}{ Table 4} \\
\hline \multicolumn{7}{|c|}{ Specialization Index, Two-Limit Tobit Results } \\
\hline & \multicolumn{2}{|c|}{ US Data ${ }^{a}$} & \multicolumn{4}{|c|}{ Danish Data $^{b}$} \\
\hline Variable & \multicolumn{2}{|l|}{$\underline{\text { US SIQT }^{\mathrm{C}}}$} & \multicolumn{2}{|c|}{ DK SIQP $^{\mathrm{c}}$} & \multicolumn{2}{|c|}{ DK SIDT $^{\mathrm{c}}$} \\
\hline Married & 0.0073 & & 0.0016 & & -0.0524 & ** \\
\hline Years in Relationship & 0.0057 & $* \star \star \star *$ & 0.0158 & ** & -0.0065 & \\
\hline Years in Relationship Squared/100 & -0.0080 & * & -0.0560 & * & 0.0440 & \\
\hline Truncated Duration Measure & & & 0.0426 & & -0.0382 & \\
\hline Hours/Week Spent on Housework & -0.0013 & 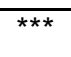 & -0.0521 & 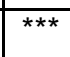 & & \\
\hline - Diary-Based & & & & & 0.0239 & ** \\
\hline \# of Housework Activities & -0.0131 & * & -0.0015 & 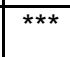 & & \\
\hline - Diary-Based & & & & & -0.0034 & 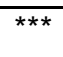 \\
\hline Single Family Dwelling & 0.0137 & & 0.0054 & & 0.0275 & \\
\hline 1 Child in Household & 0.0653 & 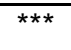 & -0.0083 & & 0.0090 & \\
\hline 2+ Children in Household & 0.0703 & 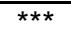 & -0.0175 & & 0.0262 & \\
\hline Child Younger than School Age & 0.0451 & 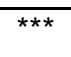 & 0.0308 & & 0.0135 & \\
\hline Man's Age & 0.0021 & 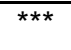 & 0.0029 & ** & 0.0017 & \\
\hline Man's Age - Woman's Age & -0.0016 & & 0.0016 & & -0.0008 & \\
\hline Man's Years of Education & -0.0210 & 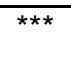 & -0.0238 & 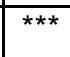 & -0.0099 & 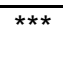 \\
\hline Man's Education - Woman's Education & 0.0163 & 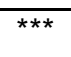 & 0.0151 & 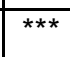 & 0.0041 & \\
\hline Number of Observations & 3675 & & 1318 & & 711 & \\
\hline \# left censored & 14 & & 96 & & 0 & \\
\hline \# right censored & 266 & & 50 & & 44 & \\
\hline \multicolumn{7}{|c|}{$\begin{array}{l}\text { a: Includes dummy variables identifying blacks, non-black/non-whites, those residing in an SMSA, those residing in } \\
\text { a rural area, those residing in the West, South, and Midwest (Eastern residence is the base case), and those missing } \\
\text { education data. }\end{array}$} \\
\hline \multicolumn{7}{|c|}{ b: These specifications also include dummy variables to identify those residing in Copenhagen and in rural areas. } \\
\hline \multicolumn{7}{|c|}{ c: $\mathrm{SI}=$ Specialization Index, $\mathrm{Q}=$ Questionnaire data, $\mathrm{D}=$ Diary data, $\mathrm{T}=$ Time use data, $\mathrm{P}=$ Participatory data. } \\
\hline
\end{tabular}




\section{Endnotes}

${ }^{1}$ Technically, what matters is the productivity of each individual at each task not the time each spends on each task, but no information on productivity with respect to housework is available.

${ }^{2}$ Also excluded were 34 couples missing age, education, household composition, or home ownership information.

${ }^{3}$ Shelton and John (1996) provide a review of several of the measurement issues.

${ }^{4}$ We deem unreasonable any report suggesting that an individual spent more than 70 hours a week on housework and any report suggesting neither partner spends any time on housework.

${ }^{5}$ While almost every household in the NSFH reports spending some time paying bills, over sixty percent report spending two hours or less on a weekly basis. The sample mean household time spent paying bills is 2.75 hours which is less than the reported time spent in any other time use except auto repair which by contrast has a lower mean but much higher variance.

${ }^{6}$ Conversely, of course, if there is more specialization in less time consuming tasks then the participatory measure will overstate actual specialization.

7 This is not the only reason for the differential as Robinson (1985) reports that time spent sleeping is also higher from questionnaire than from time diary data even when sleeping is not a secondary activity. ${ }^{8}$ Results from US data reveal a similar pattern. Using 24 hour matched time diaries for married couples age $20-60$ from the 1985 AUT survey, we obtain US SIDT values of 0.837 for weekday and 0.729 for weekend days. These are both higher than our sample average US SIQT value of 0.623 which is in turn considerably higher than our US SIQP measure.

9 Dummy variables are incorporated in the case of the US data to identify observations for which data on education are missing.

${ }^{10}$ Further examination reveals that Americans (particularly American women) report spending more time than Danes on virtually every activity, except shopping. While it is commonly the case that questionnaire reports overstate time use, the results here are notable because the Danish questionnaire data yield approximately the same mean time spent as the Danish diary data.

${ }^{11}$ We also observe this result using not entirely comparable data from the 1985 AUT time diary survey.

12 All these results are available upon request. 